\title{
The Value of Immediate Computerized Tomography Following Emergency Surgery for Traumatic Brain Injury: Experience in A Tertiary Center in Egypt
}

\author{
MOHAMMED F. ADEL ALI, M.D.; HASHEM ABOUL-ELA, M.D.; AHMED ALI MOHAMED, M.D. and \\ AHMED M. SALAH, M.D.
}

The Department of Neurosurgery, Faculty of Medicine, Cairo University

\begin{abstract}
Background: Traumatic brain injury remains a major cause of death and disability all over the world. In Egypt it represents a major public health problem, representing $17.2 \%$ of trauma patients. Various factors determine the prognosis after TBI, the primary insult, which is irreversible and the secondary insults which continue to evolve during the subsequent period after trauma.
\end{abstract}

Aim of Study: In this study, we examined the value of immediate post-operative head CT scans in trauma patients to assess its efficacy and role in returning back to operation room.

Results: We prospectively studied 145 patients with head injury who underwent surgery at Kasr Al-Ainy Hospitals during a period of 4 months between 10/2018 and 1/2019. All patients had immediate follow-up CT within 2 hours and another follow-up within 48 hours. The results of the immediate CT were: 121 cases improved (83.4\%), expected worsening in 14 patients $(9.7 \%)$ out of which 5 patients had redo surgery, unexpected worsening in 8 patients $(5.5 \%)$ out of which 2 patients had redo surgery and 2 patients with unexpected new fining (none of them required redo). The 48 hours CT revealed no change in 133 patients (91.\%), unexpected new finding in 12 patients $(8.3 \%)$ most of these changes were in patients with ASDH.

Conclusion: Unexpected change in the neurological examination was the single most influential factor in determining the need for redo surgery. The low-cost, meticulous neurological examination appears to be superior to a routine CT scan in determining return to the operation room.

Key Words: Traumatic brain injury - Computed tomography - Head injury requiring craniotomy.

\section{Introduction}

TRAUMATIC Brain Injury (TBI) remains a major cause of death and disability all over the world

Correspondence to: Dr. Mohammed F. Adel Ali, The Department of Neurosurgery, Faculty of Medicine, Cairo University
[1,2]. In Egypt it poses a major public health problem, representing $17.2 \%$ of trauma patients [3]

Various factors are attributed to the prognosis after TBI. The major factor is thought to be the primary insult, which is irreversible. However, the reversible secondary insults, which continue to evolve during the subsequent hours and days after the initial insult, also have a role in determining the outcome of TBI. Improved outcomes ensue by prevention or reduction of this phenomenon [4].

TBI requiring surgery is the severe form of the spectrum of TBI, and in these cases prevention of secondary injury is particularly challenging. Although repeat head Computed Tomography (CT) scans are a key component of the management of these patients, the timing of these studies and their efficacy regarding the impact on patient care remain undefined. Also in the absence of worsening of neurologic examination, these patients may not undergo post-op. CT for several hours after craniotomy $[\mathbf{5 , 6 ]}$.

A trip to the CT scanner may have significant risks on a vulnerable patient as in the multiple trauma patient. These repeated scans also often hinder the working capacity of the radiology department in the institute [7].

In this study, we examined value of postoperative head CT scans on the clinical course of patients with TBI that required surgery, especially in relation to the need for reoperation.

\section{Clinical Material and Methods}

In this prospective study, we studied 145 patients with head injury who underwent surgery at Kasr Al-Aini Hospital Cairo University during a 
period of 4 months from October 2018 to January 2019.

Data collection included demographic information; age, mode of injury, Glasgow Coma Score (GCS) at admission, after surgery, and at time of discharge, neurological examination on admission, findings in initial CT brain, and hospital length of stay (LOS).

Initial post-operative CT scan was obtained for all cases within 2 hours after operation and this was categorized according as improved, unchanged, expected worse, unexpected worse, or unexpected new findings (NF). Findings that were rated as expected worse were those that could be reasonably expected given the trauma severity, other systems injury, patient who had delayed recovery from anesthesia, a change in the pre-operative neurological examination findings, unexpected neurological examination. An unexpected new finding was defined as any finding discovered on post-op CT that was not present on pre-operative scan. An unexpected worse was designated when the worsening on post-op. CT was not expected based on the severity of injury.

During the trip to the post-op. CT, all patients were accompanied by a critical care nurse and, ICU doctor and neurosurgery resident.

All cases were managed by a standard regimen that maintained prevention of secondary brain insults. It included: A $30^{\circ}$ head elevation; maintenance of a normovolemic, normothermia and normo-glycemia states and in intubated patients (ventilation to keep $\mathrm{PaO}_{2}$ at a minimum of $100 \mathrm{mmHg}$ and $\mathrm{PaCO}_{2}$ at $35 \mathrm{~mm} \mathrm{Hg}$ ).

Follow-up CT scans (obtained within 48 hours after the immediate post-operative CT) were evaluated, and were recategorized as unchanged or delayed worse which was defined as worsening observed on CT scans obtained after the first postop CT.

Patient outcome was evaluated using the fivepoint Glasgow Outcome Scale (GOS) after 6 months of follow-up review; for statistical purposes, we limited outcome to two groups-favorable and unfavorable [8]. Patients in the upper two GOS outcome groups (good recovery and moderate disability) were considered to have a favorable outcome. Patients in the lower three outcome groups (severe disability, vegetative state, or death) were considered to have a poor outcome.

\section{Statistical analysis:}

Data were statistically described in terms of mean \pm Standard Deviation ( \pm SD), median and range, or frequencies (number of cases) and percentages when appropriate. Comparison of numerical variables between the study groups was done using Mann Whitney U-test for independent samplęs. For comparing categorical data, Chi-square $(\chi)$ test was performed. Exact test was used instead when the expected frequency is less than 5. $p$ values less than 0.05 was considered statistically significant. All statistical calculations were done using computer program IBM SPSS (Statistical Package for the Social Science; IBM Corp, Armonk, NY, USA) release 22 for Microsoft Windows.

\section{Results}

\section{Patient characteristics:}

During this 4-months study, a total of 266 patients were admitted to our Emergency Department. We studied 145 patients $(54.4 \%)$ who were operated upon. There were 154 surgeries performed; 145 primary surgeries and 9 redo surgeries. There were 125 male patients $(86.2 \%)$ and 20 female patients (13.8\%). The age ranged from 3 to 55 years, with a mean age of 29 years. Mode of trauma included: Fall From Height (FFH) in 32 patients (22.1\%), Fall on the Ground (FOG) $1(0.7 \%)$, Isolated Head Trauma (IHT) in $67(46.2 \%)$ and Road Traffic Accident (RTA) in 45 (31\%). On admission the level of consciousness in 44 patients was disturbed (DCL) (30.3\%), whereas 101 patients $(69.7 \%)$ were Fully Conscious (FC). In the DCL patients, 7 were presenting with GCS 4-7 (15.9\%) and 37 were presenting with GCS 8-14 (84.1\%). As for neurological examination on admission, 133 patients had Full Motor Power (FMP) (91.7\%) and 12 had weakness $(8.3 \%)$.

\section{Ct scan findings on admission:}

On admission we found 75 cases of Extradural Hematoma (EDH) (51.7\%), 34 Compound Depressed Fracture (CDF) (23.4\%), 23 Acute Subdural Hematoma (ASDH) (15.9\%), 8 Simple Depressed Fracture (SDF) (5.5\%) and 5 Traumatic Intracerebral Hematoma (TICH) (3.4\%) (Table 1).

Table (1): Indication for surgery in 145 patients.

\begin{tabular}{ll}
\hline Indication for surgery & No. $(\%)$ \\
\hline - Acute subdural hematoma & $23(15.9 \%)$ \\
- Compound depressed fracture & $34(23.4 \%)$ \\
- Extradural hematoma & $75(51.7 \%)$ \\
- Simple depressed fracture & $8(5.5 \%)$ \\
- Traumatic intracerebral hemorrhage or & $5(3.4 \%)$ \\
contusion & \\
\hline
\end{tabular}




\section{Post-operative course:}

Regarding the post-operative clinical condition: $130(89.7 \%)$ patients were unchanged or improved regarding the conscious level. One patient with CDF had a redo surgery due to a missed bone chip in the epidural space, and 15 patients were deteriorated (10.3\%); this deterioration was either drop in conscious level or more or new weakness. Of these 15 patients, 8 were reoperated.

\section{Immediate post-operative CT scans findings:}

All patients had immediate post-operative CT within one to two hours post-operative. On viewing the results of the immediate follow-up CT we found that 121 cases were improved $(83.4 \%)$ which means proper evacuation of hematoma or elevation of depressed bone chip with proper hemostasis and no new pathologies encountered in images. Expected worsening was found in 14 patients $(9.7 \%)$ out of which 5 patients had redo surgery. Unexpected worsening of images was seen in 8 patients $(5.5 \%)$ out of which 2 patients had redo surgery. Two patients had an unexpected NF in post-operative images and none of them required reoperation (Table 2).

There were 4 cases of ASDH; 2 of them had deterioration of GCS post-operatively and were found to have rebleeding, one had more weakness in the contralateral side to the hematoma and was found to have a large contusion in post-operative images which was not present in pre-operative images, and the last was found to have weakness in the same side of hematoma which was not present pre-operatively and was found to have contralateral contusion with considerable Midline shift (MLS). One case with EDH had a drop in GCS postoperatively from 14 to 8 , owing to massive recollection and was reoperated (this patient was a 4year-old male with a fibrinogenemia Fig. (1). The remaining 2 cases had TICH. The first developed weakness on the same side of hematoma and was found to have a contralateral contusion. The other one showed deterioration of GCS post-operatively from 9 to 4 and was found to have a massive MLS with severe edema Fig. (2). This case was reoperated by decompressive craniotomy.

Table (2): Results of the comparison of post-operative findings with pre-operative findings in 145 patients who underwent ct scan after operation.

\begin{tabular}{lll}
\hline Post-op. CT compared with pre-op. & \multicolumn{2}{c}{ No. (\%) } \\
\hline Improved & 121 & $(83.4 \%)$ \\
Expected worse & 14 & $(9.7 \%)$ \\
Unexpected worse & 8 & $(5.5 \%)$ \\
Unexpected new findings & 2 & $(1.4 \%)$ \\
\hline
\end{tabular}

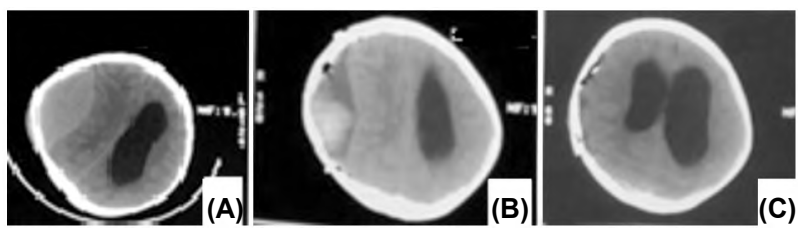

Fig. (1): Images of a 4-year-old male patient with right parietal EDH and with afibrinogenemia operated upon by excision and on immediate follow-up CT showed recollection and clinically showed delayed recovery and was reoperated and recovered with no deficit (A: Pre-operative, B: Immediate post-operative $\mathrm{C}$ : After reoperation).
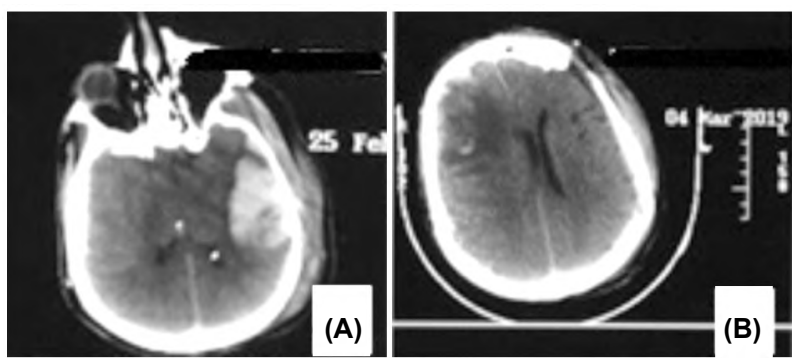

Fig. (2): A 46-year-old male patient came with GCS 8/15 with TICH, operated upon by evacuation. Post-operatively, the patient was 4/15. Immediate follow-up CT showed aggressive edema with MLS and was re operated by decompressive craniotomy. GCS after ${ }^{2 n d}$ operation was $5 / 15$ and admitted to ICU. (A: Pre-operative, B: Immediate post-op.).

\section{Ct scans after 48 hours findings:}

All patients had follow-up CT scan after 48 hours and it revealed no change compared to the immediate follow-up CT in 133 patients (91.\%) but we found unexpected new finding in 12 patients (8.3\%) as follows: 6 patients of ASDH developed infarction or contusion or edema and none of them required redo, 2 patients of TICH developed infarction, 2 EDH patients developed infarction Fig. (3), and 2 patients of CDF developed underlying contusion which presented as contralateral weakness.

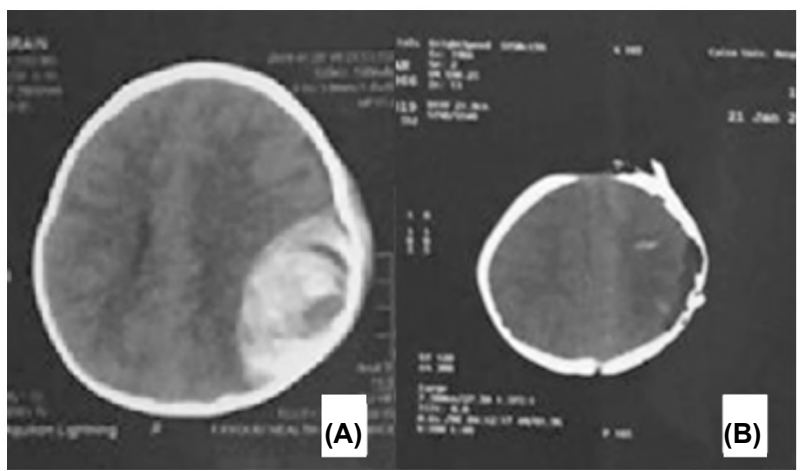

Fig. (3): A 1.5-year-old male with left parietal EDH (FC with no deficit) was operated upon by evacuation. The immediate CT showed proper evacuation. The 48 hours CT showed venous infarction and contusion. The patient was clinically intact, and no further procedures were required. 


\section{Outcome:}

Eventually 127 patients went home FC with GOS ranging from 4 to 5 , nine patients were vegetative GOS 3 (they also went home with the help of special nurse), four patients were transferred to rehabilitation center with GOS 2 and five patients died. The average hospital stay period in the uncomplicated fully conscious cases was 3 days, but this period changed according to GCS on admission, the need for reoperation and the post-operative GCS (Table 3).

Table (3): Outcome for 145 patients with TBI required surgery.

\begin{tabular}{ll}
\hline Outcome & No. $(\%)$ \\
\hline DCL & $4(2.8 \%)$ \\
Death & $5(3.4 \%)$ \\
Fully conscious & $127(87.6 \%)$ \\
Vegetative & $9(6.2 \%)$ \\
\hline
\end{tabular}

Table (4): Bivariate analysis.

\begin{tabular}{|c|c|c|c|}
\hline \multirow{2}{*}{ Variable* } & \multicolumn{2}{|c|}{ Reoperation } & \multirow{2}{*}{$\begin{array}{c}p- \\
\text { value }\end{array}$} \\
\hline & Yes & No & \\
\hline \multicolumn{4}{|l|}{ Sex: } \\
\hline Male & $9(7.2 \%)$ & $116(92.8 \%)$ & \multirow[t]{2}{*}{0.642} \\
\hline Female & $0(0.0 \%)$ & $20 \quad(100 \%)$ & \\
\hline \multicolumn{4}{|l|}{ Mode of trauma: } \\
\hline FFH & $1(3.1 \%)$ & $31(96.9 \%)$ & \multirow[t]{4}{*}{0.274} \\
\hline FOG & $0(0.0 \%)$ & $1 \quad(100 \%)$ & \\
\hline IHT & $7(10.4 \%)$ & $60(89.6 \%)$ & \\
\hline RTA & $1(2.2 \%)$ & $44(97.8 \%)$ & \\
\hline \multicolumn{4}{|l|}{ GCS-on admission: } \\
\hline DCL & $9(20.5 \%)$ & $35 \quad(79.5 \%)$ & \multirow[t]{2}{*}{$<0.01$} \\
\hline FC & $0(0.0 \%)$ & $101(100 \%)$ & \\
\hline \multicolumn{4}{|l|}{ DCL score OA: } \\
\hline 4-7 & $0(0.0 \%)$ & $7 \quad(100 \%)$ & \multirow{2}{*}{0.314} \\
\hline $8-14$ & $9(24.3 \%)$ & $28(75.7 \%)$ & \\
\hline \multicolumn{4}{|l|}{ Motor deficit: } \\
\hline FMP & $8(6 \%)$ & $125(94 \%)$ & \multirow[t]{2}{*}{0.551} \\
\hline Weakness & $1(8.3 \%)$ & $11 \quad(91.7 \%)$ & \\
\hline \multicolumn{4}{|l|}{ CT on admission: } \\
\hline ASDH & $4(17.4 \%)$ & $19(82.6 \%)$ & 0.037 \\
\hline Cdf & $1(2.9 \%)$ & $33(97.1 \%)$ & 0.686 \\
\hline Edh & $2(2.7 \%)$ & $73(97.3 \%)$ & 0.091 \\
\hline Sdf & $0(0.0 \%)$ & $8 \quad(100 \%)$ & 1.0 \\
\hline $\mathrm{TICH}$ & $2(40 \%)$ & $3(60 \%)$ & 0.032 \\
\hline \multicolumn{4}{|l|}{ CT post: } \\
\hline Expected worsening & $5(35.7 \%)$ & $9 \quad(64.3 \%)$ & \multirow[t]{4}{*}{$<0.01$} \\
\hline Improved & $2(1.7 \%)$ & $119(98.3 \%)$ & \\
\hline Unexpected new finding & $0(0.0 \%)$ & $2 \quad(100 \%)$ & \\
\hline Unexpected worsening & $2(25 \%)$ & $6 \quad(75 \%)$ & \\
\hline \multicolumn{4}{|l|}{ Clinical state post-op.: } \\
\hline Deteriorated & $9(60 \%)$ & $6 \quad(40 \%)$ & \multirow[t]{2}{*}{$<0.01$} \\
\hline No change & $0(0.0 \%)$ & $130(100 \%)$ & \\
\hline \multicolumn{4}{|l|}{ Ct 48h: } \\
\hline No change & $8(6.0 \%)$ & $125(94.0 \%)$ & \multirow[t]{2}{*}{0.551} \\
\hline Unexpected new finding & $1(8.3 \%)$ & $11 \quad(91.7 \%)$ & \\
\hline
\end{tabular}

\section{Discussion}

Head CT scan is one of the most common and frequently obtained studies in a neurological surgery practice. Computerized tomography scanning is indispensable in the diagnostic and serial evaluation of patients suffering from severe head injuries and has been used as a tool for assessing outcome in such patients $[\mathbf{9 , 1 0 ]}$.

In this study, we examined the value of immediate post-operative head CT scans in trauma patients to assess its efficacy and role in returning back to operation room, we performed CT scanning directly from the recovery room after surgery for traumatic brain injury and routine scans obtained within 48 hours after surgery. These studies can expose the patients to multiple risks and also exhaust the resources of the hospital [7,11-13]. Some authors even evaluated a portable CT scanner to avoid mobilization of critically-ill patients, however it was found to be of inferior quality than a conventional CT scanner [14].

We found a rate $(6.9 \%)$ of unexpected findings on immediate post-op. CT for trauma patients requiring surgery at our trauma department during four-month period. Four (44.4\%) of the 9 patients who required resurgery in in the first day after $1 \mathrm{st}$ surgery. Relatively few (8.3\%) patients developed delayed deterioration and none of them had unexpected new findings. Our rate of unexpected NF on immediate post-op. CT is similar with published data on CT scanning after craniotomy in patients TBI. In a prospective study of 82 patients assessing the value of CT scans performed within the first 12 hours after surgery for traumatic intracranial hematoma, Lubillo et al., encountered a rate of NF on post-op. CT of $22 \%$ [15]. Also, in a retrospective analysis in a series of 95 cases with TBI requiring surgey, Caroli et al., found unexpected new findings on immediate post-op. CT that require resurgery in $29 \%$ of the 55 patients [16]. In a retrospective study of 149 patients with posttraumatic lesions required operation, Furukawa et al., found that 28 of the 43 cases who developed contralateral intracranial hematoma, $18.8 \%$ overall, on intial post-op. CT [17]. Paci et al., reported unexpected NF in 37 (20.6\%) out of 180 patients in the immediate postoperative scan [18]. In the study by Takeuchi et al., $\mathrm{NF}$ were observed in post-operative CT scans of 26 patients $(25.5 \%)$ out of 102 patients who underwent craniotomy for TBI. They added however, that the CT scans in the first hour after surgery yielded most of these findings namely 18 patients (69.2\% of the new findings) [19]. Table summarizing studies. 


\begin{tabular}{|c|c|c|c|}
\hline Author & Cases & Study type & Findings \\
\hline $\begin{array}{l}\text { - Lubillo et } \\
\text { al., } 1999\end{array}$ & $\begin{array}{l}\text { - } 82 \text { patients undergoing craniotomy for } \\
\text { traumatic hematoma CT scans was done } \\
\text { within } 12 \text { hours post-operatively. }\end{array}$ & Prospective & $\cdot 22 \% \mathrm{NF}$ \\
\hline $\begin{array}{l}\text { - Caroli et } \\
\text { al., } 2001\end{array}$ & $\begin{array}{l}\text { - } 95 \text { patients with multiple posttraumatic } \\
\text { intracranial lesions. }\end{array}$ & Retrospective & $\begin{array}{l}\text { - NF on immediate post-op. CT requiring a re } \\
\text { operation in } 29 \% \text { of the } 55 \text { cases. }\end{array}$ \\
\hline $\begin{array}{l}\text { - Fukuwara } \\
\text { et al., } 2006\end{array}$ & $\begin{array}{l}\text { - } 149 \text { patients with traumatic ICH treated by } \\
\text { hematoma evacuation. Post-craniotomy brain } \\
\text { CT scans showed unilateral hematoma in } 106 \\
\text { patients and bilateral in } 43 \text {. }\end{array}$ & Retrospective & $\begin{array}{l}\text { - } 28 \text { of the } 43 \text { patients who developed } \\
\text { contralateral intracranial hematoma, } 18.8 \% \\
\text { were identified on immediate post-op CT. }\end{array}$ \\
\hline $\begin{array}{l}\text { - Paci et al., } \\
2008\end{array}$ & $\begin{array}{l}\text { - } 199 \text { patients with TBI who underwent } \\
\text { craniotomy. }\end{array}$ & Retrospective & $\begin{array}{l}\text { - } 37(20.6 \%) \text { out of } 180 \text { patients in the } \\
\text { immediate post-operative scan. Subdural } \\
\text { hematoma as an indication for surgery was } \\
\text { the only variable associated with unexpected } \\
\text { findings. }\end{array}$ \\
\hline $\begin{array}{l}\text { - Takeuchi } \\
\text { et al., } 2013\end{array}$ & $\begin{array}{l}\text { - } 102 \text { patients who underwent decompressive } \\
\text { craniectomy (DC) for TBI. }\end{array}$ & Retrospective & $\begin{array}{l}\text { - NF were observed in post-operative CT scans } \\
\text { of } 26 \text { patients }(25.5 \%) \text {. High yield in first } \\
\text { hour CT scan } 18 \text { patients }(69.2 \% \text { of the new } \\
\text { findings). }\end{array}$ \\
\hline - This study & $\begin{array}{l}\text { - } 145 \text { patients with head injury who underwent } \\
\text { surgery. } 9 \text { cases went to the OR again. }\end{array}$ & Prospective & $\begin{array}{l}\text { - Four }(44.4 \%) \text { of the } 9 \text { were reoperated patients } \\
\text { in immediate post-operative CT. }\end{array}$ \\
\hline
\end{tabular}

Several intracranial hemorrhagic lesions have been reported to appear (including subdural hematomas or epidural hematomas or contusion) at the opposite side to the craniectomy, or the same side. It is postulated that remote bleeding after DC may be due to brain shift. Some post-operative hemorrhagic lesions could be explained by lesions that were not detected on initial scans, but continued to evolve $[19,20]$. Paci et al., reported that subdural hematoma as an that require surgery was the only variable associated with unexpected findings, which were defined as NFs, or unexpected worsening, which was assigned when the worsening was not within reasonable expectations on the postoperative CT. This may be caused by gravity of the primary injury causing damage to the underlying brain. Acute SDH is considered one of the most fatal types of TBI [18]. We found a similar rate as ASDH and TICH was associated with a high rate of reoperation ( $p$-values 0.037 and 0.034 respectively). Four of the 9 patients (40\%) who went to the OR again had ASDH and 2 of them (22.2\%) had TICH.

From our data we conclude that a new, unexpected neurological finding is the most significant factor that will lead to emergency return to the OR (60\% of the 9 patients who were reoperated) $p$ value $<0.01$. These data are similar to what is found in the previously published data. In another series, $17(38 \%)$ of 45 cases reoperated after an immediate post-opertive CT scan was obtained [21]. In a similar study, 7 (4\%) of 179 patients with mild TBI needed operative intervention. All 7 had a changes in their examination results. The authors concluded that a routine, repeat head CT scan in patients who pre- sented with mild TBI was unnecessary [22]. In another study, a repeat head CT for mild head injury was unnecessary in patients with no new findings on their neurological examination [23] .

Also immediate CT scans may give a false sense of security, leading to patient ignorance in which less frequent and closed monitoring of neurological examination performed. This is demonstrated by our data, in that of the 11 patients had unexpected new findings in subsequent scans obtained within 48 hours post-operatively.

\section{Conclusion:}

Our study demonstrates that the simple frequent neurological examination appears to be superior to early post-operative CT scan in determining return to the OR in patients with traumatic brain injury. Furthermore, post-operative CT scans done too early was cost-effective and had low predictive value of in patients with normal findings on neurological examination.

\section{References}

1- SUBEDI P. and SHILPAKAR S.: Correlation of D-Dimer level with outcome in traumatic brain injury. J. Soc. Surg. Nepal. [Internet]. Jul. 4, 17 (1 SE-Original Articles). Available from: https://www.nepjol.info/index.php/JSSN/ article/view/15177, 2016.

2- SHERIFF F.G. and HINSON H.E.: Pathophysiology and clinical management of moderate and severe traumatic brain injury in the ICU. Semin Neurol [Internet]. Feb., 35 (1): 42-9. Available from: http://www.ncbi.nlm.nih.gov/ pubmed/25714866, 2015.

3- MONTASER T., HASAN A. and IBRAHIM A.: Epidemiology of moderate and severe traumatic brain injury in 
Cairo University Hospital in 2010. Scand J. Trauma Resusc. Emerg. Med. [Internet]. Sep. 9, 21 (Suppl 2): A4A4. Available from: https://www.ncbi.nlm.nih.gov/pmc/ articles/PMC3844367/, 2013.

4- BAUM J., ENTEZAMI P., SHAH K. and MEDHKOUR A.: Predictors of Outcomes in Traumatic Brain Injury. World Neurosurg. [Internet]. Jun., 90: 525-9. Available from: https://linkinghub.elsevier.com/retrieve/pii/ S1878875015016824, 2016.

5- MIRVIS S.E., SHANMUGANATHAN K., DONOHUE R., WHITE W.H., FRITZ S. and HARTSOCK R.: Mobile computed tomography in the trauma/critical care environment: Preliminary clinical experience. Emerg. Radiol. [Internet]. Jul., 4 (4): 212-7. Available from: http:// link. springer.com/10.1007/BF01508173, 1997.

6- BULLOCK M.R., CHESNUT R., GHAJAR J., GORDON D., HARTL R., NEWELL D.W., et al.: Guidelines for the Surgical Management of Traumatic Brain Injury Author Group: Acknowledgments. Neurosurgery [Internet]. Mar., S2-vi. Available from: http://content.wkhealth. com/linkback/openurl?sid=WKPTLP:landingpage\&an= 00006123-200603001-00006, 2006.

7- WAYDHAS C.: Intrahospital transport of critically ill patients. Crit. Care [Internet]. 3 (5): R83-9. Available from: http://www.ncbi.nlm.nih.gov/pubmed/11094486, 1999.

8- JENNETT B. and BOND M.: Assessment of outcome after severe brain damage. Lancet (London, England) [Internet]. Mar. 1, 1 (7905): 480-4. Available from: http:// . www.ncbi.nlm.nih.gov/pubmed/46957. 1975.

9- TOUTANT S.M., KLAUBER M.R., MARSHALL L.F., TOOLE B.M., BOWERS S.A., SEELIG J.M., et al.: Absent or compressed basal cisterns on first CT scan: Ominous predictors of outcome in severe head injury. $\mathrm{J}$. Neurosurg. [Internet]. Oct., 61 (4): 691-4. Available from: https://theins.org/view/journals/i-neurosurg/61/4/articlep691.xml. 1984.

10- MURPHY A., TEASDALE E., MATHESON M., GALBRAITH S. and TEASDALE G.: Relationship Between CT Indices of Brain Swelling and Intracranial Pressure After Head Injury BT-Intracranial Pressure V. In: Ishii S, Nagai H, Brock M, editors. Berlin, Heidelberg: Springer Berlin Heidelberg, p. 562-6, 1983.

11- FOROGLOU G., PATSALAS I. and KONTOPOULOS B.: The timing of CT. Neurosurg. Rev. [Internet]. 12 Suppl 1: 169-74. Available from: http://www.ncbi.nlm.nih.gov/ pubmed/2812367, 1989.

12- OERTEL M., KELLY D.F., McARTHUR D., BOSCARDIN W.J., GLENN T.C., LEE J.H., et al.: Progressive hemorrhage after head trauma: Predictors and consequences of the evolving injury. J. Neurosurg. [Internet]. Jan., 96 (1): 109-16. Available from: https://thejns.org/view/ journals/j-neurosurg/96/1/article-p109.xml, 2002.

13- GIMENEZ F.M.P., De CAMARGO W.H.B., GOMES A.C.B., NIHEI T.S., ANDRADE M.W.M., VALVERDE M.L. De A.F.S., et al.: Analysis of Adverse Events during Intrahospital Transportation of Critically Ill Patients. Crit. Care Res. Pract. [Internet]. 2017: 6847124. Available from: http://www.ncbi.nlm.nih.gov/pubmed/29062574, 2017.
14- ABDULLAH A.C., ADNAN J.S., A. RAHMAN N.A. and PALUR R.: Limited Evaluation of Image Quality Produced by a Portable Head CT Scanner (CereTom) in a Neurosurgery Centre. Malaysian J. Med. Sci. [Internet]. 24 (1): 104-12. Available from: http://journal.usm.my/journal/ mjms241_11BC.pdf, 2017.

15-LUBILLO S., BOLAÑOS J., CARREIRA L., CARDEÑOSA J., ARROYO J. and MANZANO J.: Prognostic value of early computerized tomography scanning following craniotomy for traumatic hematomas. J. Neurosurg. [Internet]. Oct., 91 (4): 581-7. Available from: https:// theins.org/view/journals/j-neurosurg/91/4/article-p581.xml, 1999.

16- CAROLI M., LOCATELLI M., CAMPANELLA R., BALBI S., MARTINELLI F. and ARIENTA C.: Multiple intracranial lesions in head injury. Surg. Neurol. [Internet]. Aug., 56 (2): 82-8. Available from: http://linkinghub. elsevier.com/retrieve/pii/S0090301901005407, 2001.

17- FURUKAWA M., KINOSHITA K., EBIHARA T., SAKURAI A., NODA A., KITAHATA Y., et al.: Clinical characteristics of post-operative contralateral intracranial hematoma after traumatic brain injury BT- Brain Edema XIII. In: Hoff JT, Keep RF, Xi G, Hua Y, editors. Vienna: Springer Vienna; p. 48-50, 2006.

18- PACI G.M., SISE M.J., SISE C.B., SACK D.I., SWAN SON S.M., HOLBROOK T.L., et al.: The need for immediate computed tomography scan after emergency craniotomy for head injury. J. Trauma-Inj. Infect Crit. Care, 64 (2): 326-33, 2008.

19- TAKEUCHI S., TAKASATO Y., SUZUKI G., MAEDA T., MASAOKA H., HAYAKAWA T., et al.: Computed Tomography After Decompressive Craniectomy for Head Injury BT- Brain Edema XV. In: Katayama Y, Maeda T, Kuroiwa T, editors. Vienna: Springer Vienna, p. 235-7, 2013.

20- ALAHMADI H., VACHHRAJANI S. and CUSIMANO M.D.: The natural history of brain contusion: An analysis of radiological and clinical progression. J. Neurosurg. [Internet]. May, 112 (5): 1139-45. Available from: https://thejns.org/view/journals/j-neurosurg/1 12/5/articl ep1139.xml, 2010.

21- BROWN C.V.R., ZADA G., SALIM A., INABA K., KASOTAKIS G., HADJIZACHARIA P., et al.: Indications for Routine Repeat Head Computed Tomography (CT) Stratified by Severity of Traumatic Brain Injury. J. Trauma Inj. Infect. Crit. Care [Internet]. Jun., 62 (6): 1339-45. Available from: https://insights.ovid.com/crossref? an=00005373-200706000-00004, 2007.

22- VELMAHOS G.C., GERVASINI A., PETROVICK L., DORER D.J., DORAN M.E., SPANIOLAS K., et al.: Routine repeat head CT for minimal head injury is unnecessary. J. Trauma [Internet]. Mar., 60 (3): 494-9-501. Available from: http://www.ncbi.nlm.nih.gov/pubmed/ 16531845, 2006.

23- SIFRI Z.C., HOMNICK A.T., VAYNMAN A., LAVERY R., LIAO W., MOHR A., et al.: A prospective evaluation of the value of repeat cranial computed tomography in patients with minimal head injury and an intracranial bleed. J. Trauma [Internet]. Oct., 61 (4): 862-7. Available from: http://www.ncbi.nlm.nih.gov/pubmed/17033552, 2006. 


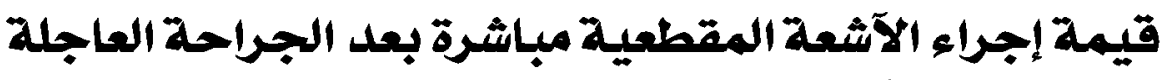

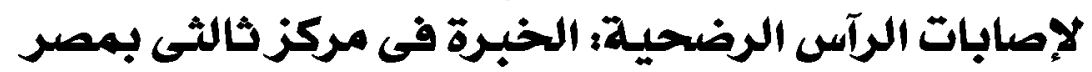

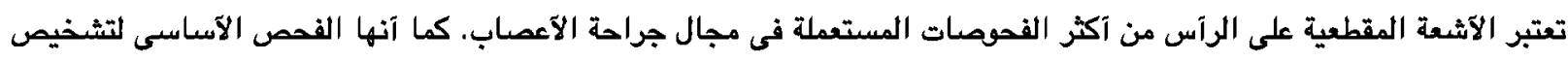

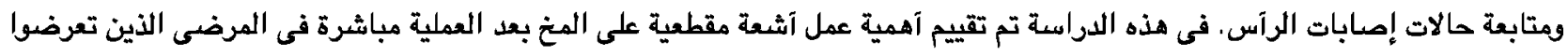

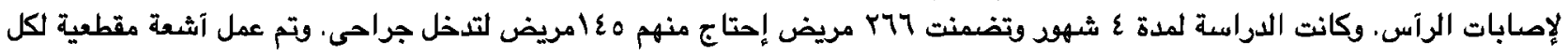

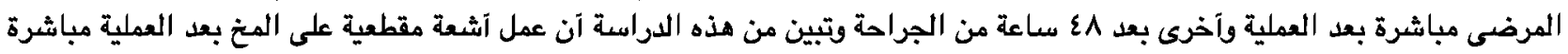

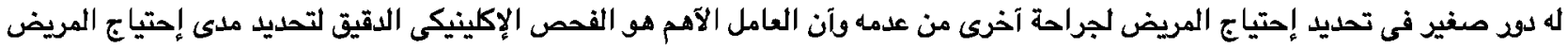

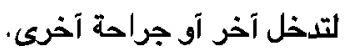

